\title{
Numerical Prediction of Oil Formation Volume Factor at Bubble Point for Black and Volatile Oil Reservoirs Using Non- Linear Regression Models
}

\author{
El-hoshoudy AN* and Desouky SM \\ Egyptian Petroleum Research Institute, Production Department, PVT- lab, Cairo, \\ Egypt
}

\section{Research Article \\ Volume 2 Issue 2}

Received Date: February 20, 2018

Published Date: March 05, 2018

*Corresponding author: Abdelaziz Nasr El-hoshoudy, Egyptian Petroleum Research Institute, Production Department, PVT- lab., Cairo, Egypt, Email: azizchemist@yahoo.com

\section{Abstract}

Empirical Pressure-Volume- Temperature PVT correlations acquired increased attention for prediction of reservoir fluid properties. Oil formation volume factor is one of the most important pressure-volume- temperature properties of crude oils for reservoir evaluation and simulation. Experimental PVT analysis including constant mass depletion and differential liberation (vaporization) tests carried out on black and light volatile oil samples covering a great range of physical properties. An empirical correlation predicting bubble point oil formation volume factor was developed based on (100) data set covering different Egyptian oil production regions built up using non- linear regression models. Assessment and validation of the developed correlation were estimated by statistical and graphical error analysis. Statistical analysis parameters involve Average percent relative error $\left(E_{r}\right)$, Average absolute percent relative error $\left(E_{a}\right)$, Maximum absolute percent relative error $\left(E_{\max }\right)$, Minimum absolute percent relative error $\left(E_{\min }\right)$, Root mean square error $\left(\mathrm{E}_{\mathrm{rms}}\right.$ ), and Standard deviation (S). The obtained results indicate high accuracy of the developed correlation with a correlation coefficient ( $r=0.988$ ) compared to the published correlations. Scientific contribution of the newly correlation results from the fact that it depends on experimental field data, new correlating parameters not considered before that in published literatures are introduced depending on separator conditions and has a wide application range for petroleum engineers especially when actual PVT laboratory data are missed or in case of highly costed analysis.

Keywords: Oil formation volume factor $\left(\mathrm{B}_{0}\right)$; Regression analysis; PVT analysis and Empirical correlation 


\section{Petroleum \& Petrochemical Engineering Journal}

Abbreviations: PVT: Pressure-Volume- Temperature; FVF: Formation Volume Factor

\section{Introduction}

PVT data of reservoir fluids are important in oil and gas engineering calculations and reservoir numerical simulations. These properties are measured experimentally in laboratory based on downhole or recombined surface samples [1]. One of these properties is the oil formation volume factor (FVF) at the bubble point $\left(\mathrm{B}_{\mathrm{ob}}\right)$, which detected experimentally through differential liberation test [2] and used in calculating various parameters such as the depletion rate, oil in place, predicting the future of the reservoir, optimizing the production rate and some other simulation and optimization techniques [3]. $\mathrm{B}_{\mathrm{ob}}$ defined as the volume of reservoir oil that occupied at the saturation pressure and reservoir temperature by stock tank oil barrel plus any dissolved gas in the oil at that pressure and temperature [4]. Generally, oil FVF can be expressed mathematically as Equation (1);

$$
B_{o}=\frac{\left(V_{o}\right)_{P, T}}{\left(V_{o}\right)_{s c}}
$$

(Equation 1)

where $\mathrm{Bo}=$ oil formation volume factor, $\mathrm{bbl} / \mathrm{STB},(\mathrm{Vo}) \mathrm{P}, \mathrm{T}=$ volume of oil under pressure $\mathrm{p}$ and temperature $\mathrm{T}$, and (Vo)sc $=$ volume of oil is at standard conditions [5]. Although most PVT data determined experimentally in lab but, petroleum engineers may resort to empirical correlation due to; samples collected are not reliable, budget constraints, PVT analyses are not available when needed, quality check lab analysis, estimating the potential reserves to be found in an exploration prospects, and evaluating the original oil in place and reserve for a newly discovered area in addition to time saving as has been discussed by wood [6-9].

Empirical correlations involve simple calculations and do not require neither to be matched with experimental data nor detailed fluid data. These correlations usually developed for regional geographical provinces with given chemical composition of reservoir fluid and data range $[4,7]$. Thus, generalized accurate PVT relations are scarce. Most empirical PVT relations were developed by multiple linear or non-linear regression techniques, others used graphical techniques $[7,10]$. During the past decades, several empirical correlations for prediction of (Bob) have been proposed and demonstrated in the literature, based on linear regression, nonlinear multiple regression, and graphical techniques [4]. These correlations based mainly on the hypothesis that the oil FVF is a strong function of the solution gas-oil ratio (Rs), the reservoir temperature (T), the gas specific gravity $(\gamma \mathrm{g})$, and the oil specific gravity $(\gamma o)$ [1]. These correlations reported in literature M Hemmati, R Kharrat [6], Standing M [11], Vazquez M, Beggs HD [12], Glaso O [13], Al-Marhoun MA [14], AbdulMajeed GH, Salman NH [15], Dokla M, Osman M [16], AlMarhoun MA [17], Macary S, El-Batanoney M [18], Omar M, Todd A [19], Petrosky G, Farshad F [20], Kartoatmodjo T, Schmidt Z [21], Frashad F, LeBlanc J, Garber J, Osorio J [22], Almehaideb R [23], El-Banbi AH, Fattah KA, Sayyouh H [24], Sulaimon A, Ramli N, Adeyemi B, Saaid I [25], Dindoruk B, Christman PG [26], Bolondarzadeh A, Hashemi S, Solgani B [27], Mehran F, Movagharnejad K, Didanloo A [28]. Detailed description of these correlations including number and origin of data set, correlating parameters ranges, relative errors percentage and mathematical expressions found in literature Fattah $\mathrm{K}$, Lashin A [1], Mahdiani MR, Kooti G [3], Edreder EA, Rahuma KM, Kalaflla HA [5], Karimnezhad M, Heidarian M, Kamari M, Jalalifar H [29], Salehinia S, Salehinia Y, Alimadadi F, Sadati SH [30], Moradi B, Malekzadeh E, Mohammad A, Awang M, Moradie P [31].

By screening of the published empirical correlations, we found that Bob reported in relation to (Rs, T, $\gamma \mathrm{g}$ and

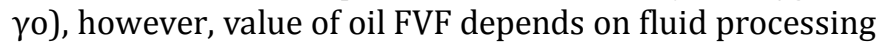
at the surface, i.e. the separator conditions (pressure and temperature), number of separation stages, before reaching the stock tank oil conditions [5]. By applying these correlations on surface samples, the relative error is higher than that in case of bottom hole samples, this may resort to neglecting of separator conditions in published correlations since variation of separator conditions greatly affect on amount of separated gas and Bo of stock tank oil. In the present work, multiple linear/nonlinear least-squares regression analysis used to build up the new correlation considering separator conditions. Moreover, accuracy of developed correlations determined through statistical error analysis (Er, Ea, Emax, Emin, S, Erms, and r) and correlation validated by other data set not used in correlation built up.

\section{Experimental PVT Analysis}

Complete PVT analysis of about 189 sample covering most production regions in Egypt was studied in our PVTlab as follow. A) Validity check of samples was carried out, after that primary study carried out through flashing a definite amount of separator oil at separator pressure and temperature to standard conditions, where some physical 


\section{Petroleum \& Petrochemical Engineering Journal}

parameters like Bo, dissolved gas-oil ratio (GOR), API of stock tank oil (STO), in addition to compositional analysis of separator and dissolved gases as well as STO determined by chromatographic techniques. B) The recombined sample then charged to mercury free PVTcell (Vinci-technologie) at reservoir temperature and pressure until it converted to one phase, where the following tests carried out [32].

\section{Constant-Mass Depletion (CMD) Tests}

Constant-composition expansion experiments carried out on crude oil to simulate the pressure-volume relations of these hydrocarbon systems. The test determine, saturation pressure (bubble-point or dew-point pressure), isothermal compressibility coefficients of the single-phase fluid above saturation pressure, gas compressibility factor, and total hydrocarbon volume as a function of pressure [33].

\section{Differential Liberation (Vaporization) Test}

In which, the dissolved gas separated from an oil sample during a decline in pressure is continuously removed from contact with the oil, and before establishing equilibrium with the liquid phase, so composition of the total hydrocarbon system varies. The test determine; amount of gas in solution as a function of pressure, oil shrinkage volume $\left(B_{0}\right)$ as a function of pressure, properties of the evolved gas including liberated gas composition, the gas compressibility factor, and the gas specific gravity and density of the remaining oil as a function of pressure [33].

\section{Empirical Correlation Development and Computation Method}

Among the empirical correlations, nonlinear regression methodology is most commonly used [1,34]. The fundamental concept of regression analysis is to fit a function of independent variables to a given set of data points in order to estimate or predict one dependent variable as accurately as possible. Regression deals with the nature of the relation between these variables. In evaluating the degree of regression, all the error or imprecision is assumed to be in the measurement of one variable called the "dependent", while the other variables are assumed to be precisely known. These precise variables are called the "independent" variables. If only one independent variable is involved then it is called simple regression analysis whereas the name multiple regression analysis is implied if more than one independent variable is present [34]. A general multiple regression model, which relates a dependent variable y to $\mathrm{k}$ predictor independent variables, $\mathrm{x}_{1}, \mathrm{x}_{2}, \ldots, \mathrm{X}_{\mathrm{k}}$, is given by Equation 2:

$y=\alpha+\beta_{1} x_{1}+\beta_{2} x_{2}+\ldots \ldots \ldots+\beta_{k} x_{k}$

(Equation 2)

Where $\alpha$ and $\beta$ 's are coefficients to be determined by the regression analysis and expressed in matrix form as follow [34].

$$
\left[\begin{array}{ccccc}
1 & x_{11} & x_{12} & . . & x_{1 n} \\
1 & x_{21} & x_{22} & . . & x_{2 n} \\
1 & x_{31} & x_{32} & . . & x_{3 n} \\
1 & . . & . . & . . & . . \\
1 & . . & . . & . . & . . \\
1 & . . & . . & . . & . . \\
1 & x_{n k 1} & x_{n k 2} & . . & x_{n k n}
\end{array}\right]\left[\begin{array}{l}
\alpha \\
\beta_{1} \\
\beta_{2} \\
. . \\
. . \\
. . \\
\beta_{n}
\end{array}\right]=\left[\begin{array}{l}
y_{1} \\
y_{2} \\
y_{3} \\
. . \\
. . \\
. . \\
y_{n k}
\end{array}\right]
$$

(Equation 3)

Least-squares regression technique is applied upon the nonlinear weighted values to minimize the sum-of squared residuals between measured and simulated quantities. The data fitted by a method of successive approximations $[1,35]$. The linearity or nonlinearity of the data pattern checked using scatter gram plotting. In this study, real experimental PVT data of (189) oil samples, which almost covers Egyptian oil reservoirs, have been analyzed and used. The data sets divided into two groups; the first one involves (100) data sets used for correlation development and construction, and the second one comprises (89) data sets used for correlation validation. Basic characteristics of Egyptian crude oils samples and data range are reported in Table 1. Multiple least-square regression analysis used to develop the proposed correlation as a function of reservoir pressure \& temperature, solution gas oil ratio, gas gravity, oil specific gravity, oil density at bubble point, saturation pressure (bubble point pressure), separator pressure and temperature ( $\mathrm{P}_{\text {res, }}, \mathrm{T}_{\mathrm{res}}, \mathrm{R}_{\mathrm{s}}, \boldsymbol{\gamma}_{\mathrm{g}}, \boldsymbol{\gamma}_{\mathbf{o}}, \rho_{\mathrm{ob}}, \mathrm{P}_{\mathrm{b}}, \mathrm{P}_{\mathrm{sep}}, \mathrm{T}_{\mathrm{sep}}$ ) respectively.

$$
B_{o b}=f\left(P_{r e s}, T_{r e s}, R_{s,} \gamma_{g}, \gamma_{o}, \rho_{o b}, P_{b}, P_{s e p}, T_{s e p}\right) \quad \text { (Equation 4) }
$$




\section{Petroleum \& Petrochemical Engineering Journal}

$$
\begin{aligned}
& B_{o b}=\operatorname{Exp}\left[\beta_{0}+\beta_{1} \ln P_{r e s}+\beta_{2} \ln T_{r e s}+\beta_{3} \ln R_{s}+\beta_{4} \ln \gamma_{\mathrm{g}}+\beta_{5} \ln \left(\gamma_{o}\right)\right. \\
& \left.+\beta_{6} \ln \rho_{o b}+\beta_{7} \ln P_{b}+\beta_{8} \ln P_{\text {sep }}+\beta_{9} \ln T_{\text {sep }}\right]
\end{aligned}
$$

Where,

\begin{tabular}{|c|c|c|c|}
\hline Parameters & Maximum & Minimum & Average \\
\hline $\mathrm{B}_{\mathrm{ob}}, \mathrm{bbl} / \mathrm{STB}$ & 4.4156 & 1.0340 & 1.4554 \\
\hline (Reservoir pressure, $\mathrm{P}_{\text {res }}$ ) psi $\mathrm{g}_{\mathrm{g}}$ & 6786.8000 & 896.0000 & 3250.7763 \\
\hline (Reservoir temperature, $\left.\mathrm{T}_{\text {res }}\right)^{\circ} \mathrm{F}$ & 353.0000 & 113.0000 & 202.5027 \\
\hline (Gas solubility, $\mathrm{R}_{\mathrm{s}}$ ) scf/STB & 5512.2900 & 7.6000 & 641.4711 \\
\hline Gas gravity & 1.4430 & 0.6611 & 0.9860 \\
\hline Oil gravity & 0.9944 & 0.7515 & 0.8539 \\
\hline (Density of oil at bubble point, $\rho_{\mathrm{ob}}$ ) g/cc & 0.9538 & 0.3413 & 0.7222 \\
\hline (Bubble point pressure, $\mathrm{P}_{\mathrm{b}}$ ) psi $\mathrm{g}$ & 5272.0000 & 42.0000 & 1637.7268 \\
\hline (Separator pressure, $\mathrm{P}_{\mathrm{sep}}$ ) psi $\mathrm{g}_{\mathrm{g}}$ & 1320.0000 & 8.0000 & 117.9165 \\
\hline (Separator temperature, $\mathrm{T}_{\text {sep }}{ }^{\circ} \mathrm{F}$ & 160.0000 & 30.0000 & 95.1376 \\
\hline${ }^{\circ} \mathrm{API}$ gravity & 56.8000 & 10.8000 & 34.6934 \\
\hline
\end{tabular}

$$
\begin{array}{llll}
\beta_{0}=0.307 & \beta_{1}=0.009 & \beta_{2}=-0.103 & \beta_{3}=0.123 \\
\beta_{5}=2.411 & \beta_{6}=-1.911 & \beta_{7}=-0.107 & \beta_{8}=0.004
\end{array}
$$

Table 1: Basic characteristics and data range of Egyptian crude oils samples.

\section{Results and Discussions}

The accuracy and reliability of the developed correlation checked by using both statistical and graphical error means [7].

\section{Statistical Error Analysis}

Accuracy and validity of the developed model was evaluated using the following statistical means; Average percent relative error $\left(E_{r}\right)$, Average absolute percent relative error $\left(E_{a}\right)$, Maximum absolute percent relative error $\left(E_{\max }\right)$, Minimum absolute percent relative error
$\left(E_{\min }\right)$, Root mean square error $\left(E_{\mathrm{rms}}\right)$ and Standard deviation (S) [11,12,34,36-38]. Mathematical expression of each parameter reported in literature [1]. Statistical errors of the published correlations and developed one in this study are reported in Table 2. It is observed that the developed correlation has lower root mean square error and standard deviation as compared to the published one, so it has more reliability to measured values. Moreover, the correlation coefficient of the presented correlation is $r=0.988$ which is closer to one so, we can deduce that this correlation is more accurate than any of the published ones relevant to Egyptian oil crudes.

\begin{tabular}{|c|c|c|c|c|c|c|c|}
\hline Correlations & $\mathbf{E}_{\mathbf{r}}$ & $\mathbf{E}_{\mathbf{a}}$ & $\mathbf{E}_{\mathbf{m a x}}$ & $\mathbf{E}_{\mathbf{m i n}}$ & $\mathbf{E}_{\mathbf{r m s}}$ & $\mathbf{S}$ & $\mathbf{r}$ \\
\hline Standing (1947) & -1.175 & 5.857 & 99.700 & 0.036 & 0.327 & 0.140 & 0.909 \\
\hline Vazquez and Begg (1980) & 7.167 & 8.336 & 28.592 & 0.576 & 0.184 & 0.099 & 0.930 \\
\hline Glaso (1980) & 1.499 & 5.683 & 59.893 & 0.177 & 0.206 & 0.095 & 0.933 \\
\hline Al-Marhoun (1988) & -0.149 & 4.122 & 68.912 & 0.004 & 0.219 & 0.095 & 0.919 \\
\hline Abdul-Majeed and Salman(1988) & -23.054 & 28.374 & 83.176 & 8.406 & 0.487 & 0.306 & 0.314 \\
\hline Dokla and Osman (1992) & 13.961 & 14.201 & 73.876 & 0.141 & 0.502 & 0.214 & 0.001 \\
\hline Al-Marhoun (1992) & -0.504 & 4.302 & 64.497 & 0.004 & 0.213 & 0.093 & 0.926 \\
\hline Macary and Batanoney (1992) & -11.763 & 12.221 & 194.484 & 0.030 & 0.732 & 0.305 & 0.843 \\
\hline Omar and Todd (1993) & 14.919 & 14.919 & 54.380 & 1.296 & 0.376 & 0.186 & 0.930 \\
\hline
\end{tabular}




\section{Petroleum \& Petrochemical Engineering Journal}

\begin{tabular}{|c|c|c|c|c|c|c|c|}
\hline Petrosky and Farshad (1993) & 2.039 & 4.808 & 49.389 & 0.005 & 0.177 & 0.081 & 0.930 \\
\hline Kartoamodjo and Schmidt (1994) & -0.198 & 4.047 & 62.246 & 0.005 & 0.206 & 0.090 & 0.926 \\
\hline Farshad et al. (1996) & -29.088 & 31.329 & 46.455 & 0.391 & 0.430 & 0.340 & 0.905 \\
\hline Almehaideb (1997) & -0.734 & 4.951 & 34.768 & 0.028 & 0.159 & 0.075 & 0.929 \\
\hline El-Banbi (2006) & 1.785 & 5.847 & 64.643 & 0.168 & 0.216 & 0.099 & 0.929 \\
\hline Sulaimon (2014) & 0.106 & 5.025 & 55.318 & 0.070 & 0.211 & 0.095 & 0.932 \\
\hline Dindoruk\&Christman (2001) & -2.631 & 7.613 & 195.790 & 0.028 & 0.521 & 0.220 & 0.828 \\
\hline Bolondarzadeh et al. (2006) & -4.021 & 6.598 & 59.478 & 0.132 & 0.217 & 0.107 & 0.911 \\
\hline Merhen et al. (2006) & -2.054 & 5.063 & 78.475 & 0.057 & 0.256 & 0.111 & 0.910 \\
\hline Hemmati\&Kharrat (2007) & -1.983 & 5.108 & 86.027 & 0.019 & 0.273 & 0.118 & 0.909 \\
\hline This study & -0.578 & 4.591 & 30.243 & 0.055 & 0.144 & 0.067 & 0.988 \\
\hline
\end{tabular}

Table 2: Statistical accuracy of the published and developed correlations.

\section{Graphical Error Analysis}

Graphical error analysis such as cross plot techniques was used in this study, in which the predicted results are plotted against the measured one. Trend line is drawn through predicted data, where, the closer the plotted data to this line, the higher is the accuracy and prediction capability of the correlation [1]. Graphical plots of the published and developed correlations are reported in Figures 1-20.

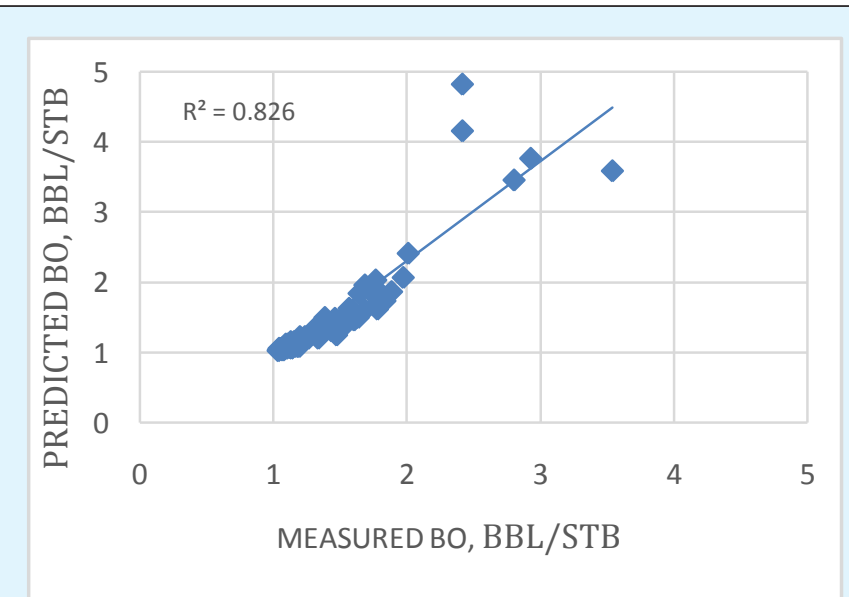

Figure 1: Standing (1947).

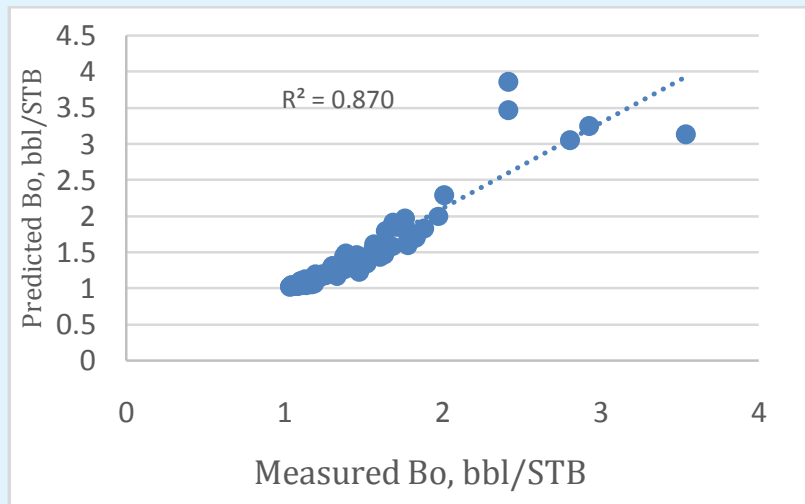

Figure 3: Glasso (1980).

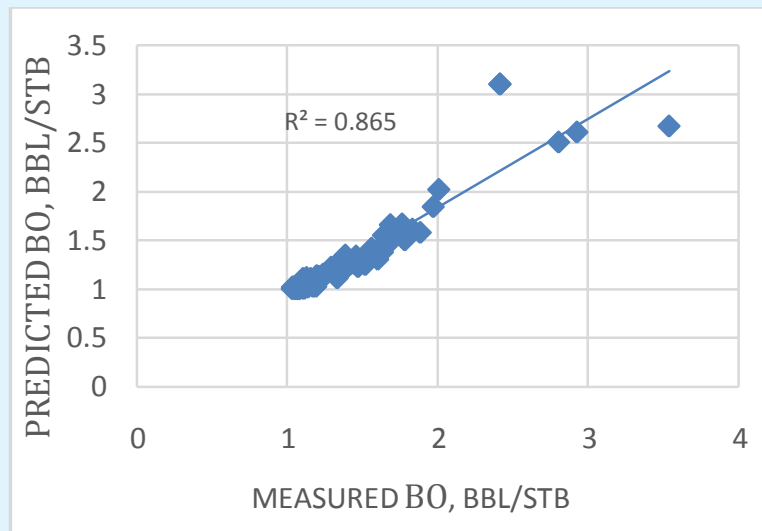

Figure 2: Vasquez and Beggs (1980).

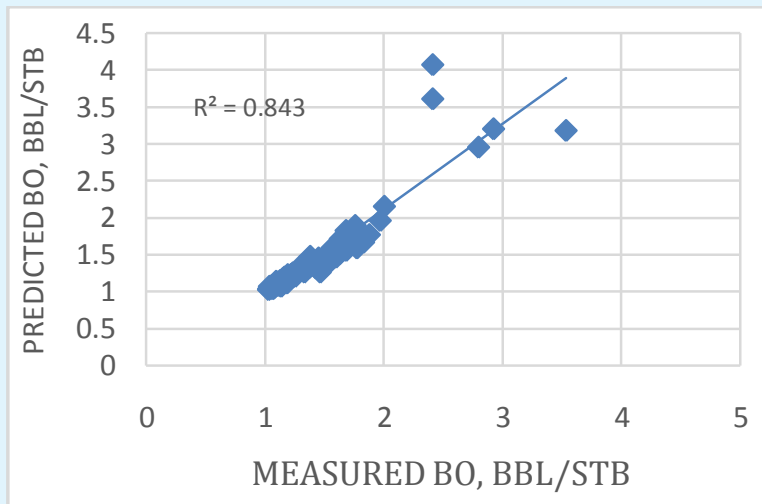

Figure 4: Al-Marhoun (1988). 


\section{Petroleum \& Petrochemical Engineering Journal}

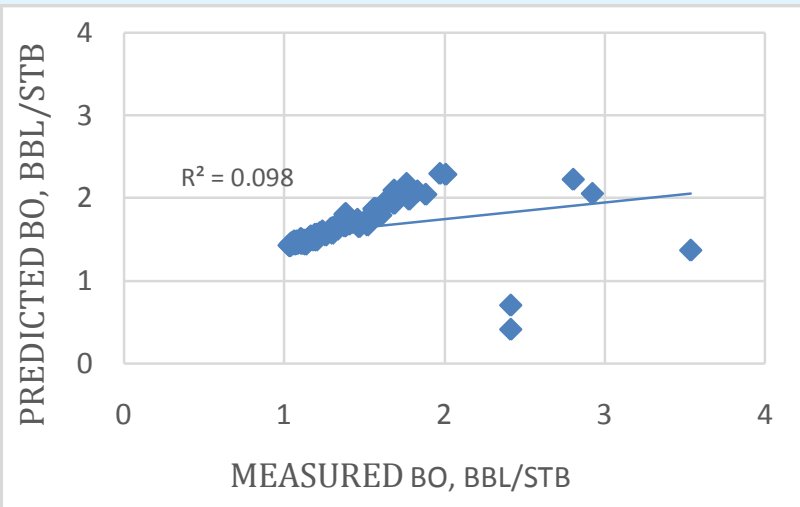

Figure 5: Abdul-Majeed and Salmoon (1988).

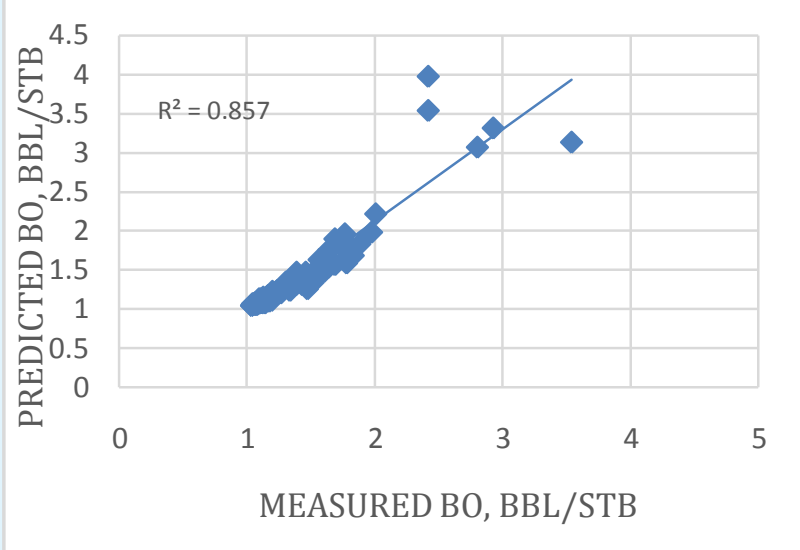

Figure 7: Al-Marhoun (1992).

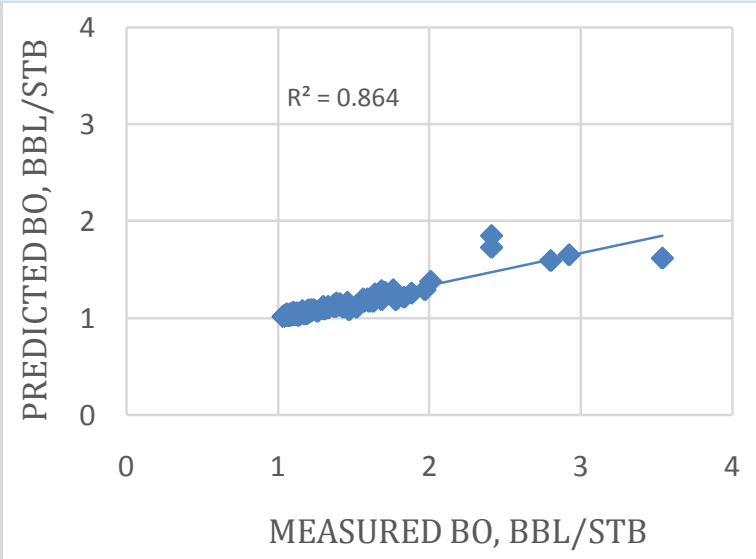

Figure 9: Omar and Todd (1993).

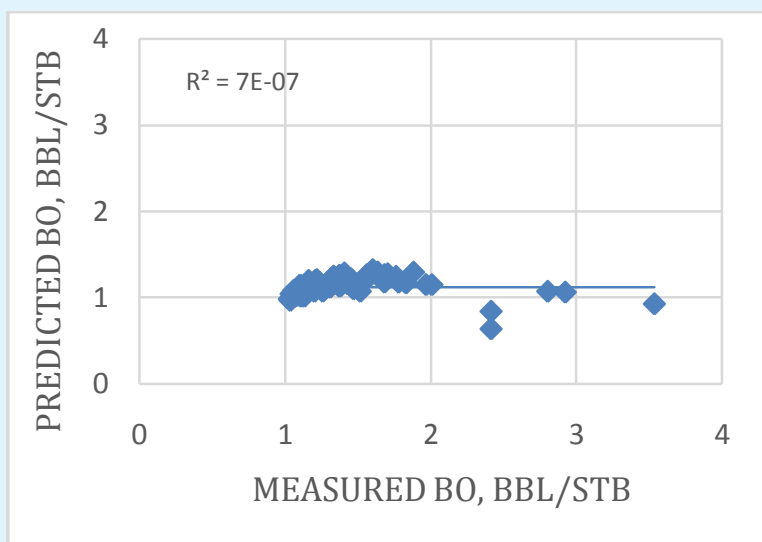

Figure 6: Dokla and Osman (1992).

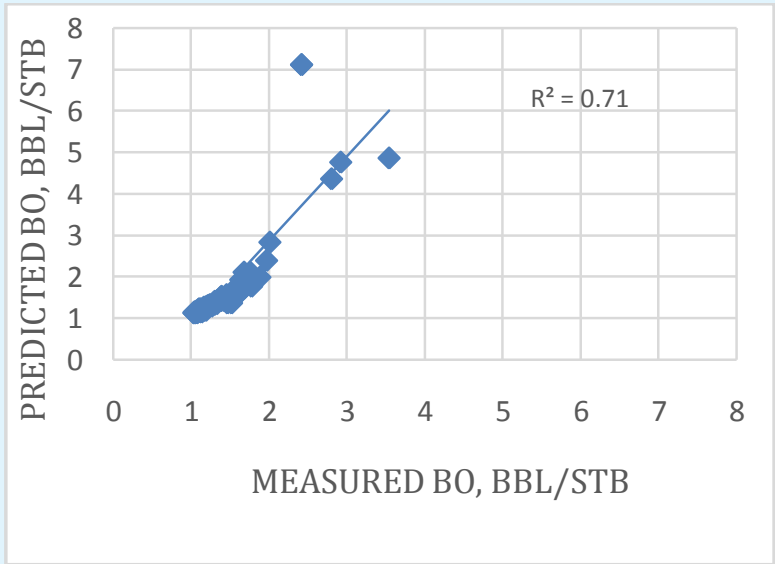

Figure 8: Macary and Batanoney (1992).

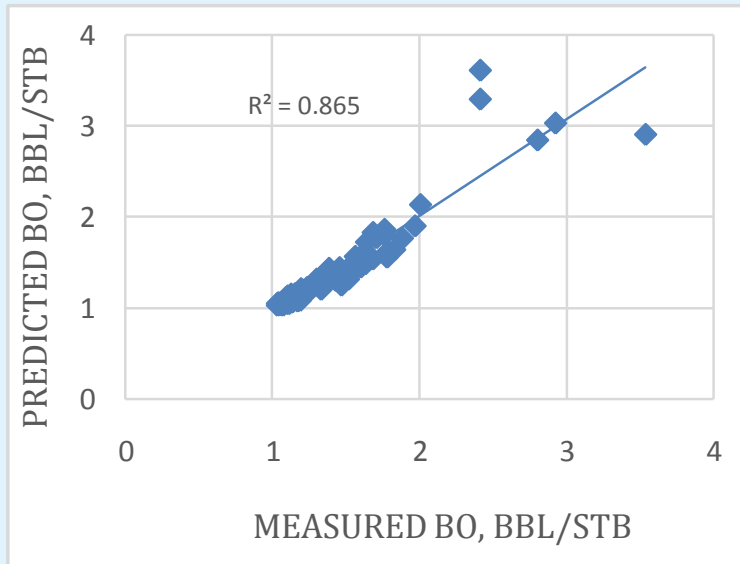

Figure 10: Petrosky and Farashad (1993). 


\section{Petroleum \& Petrochemical Engineering Journal}

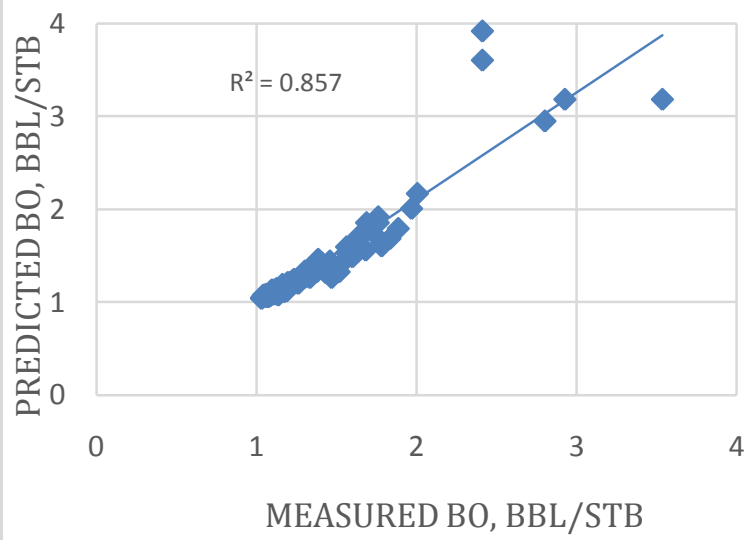

Figure 11: Kartoamodjo and Schmidt (1994).

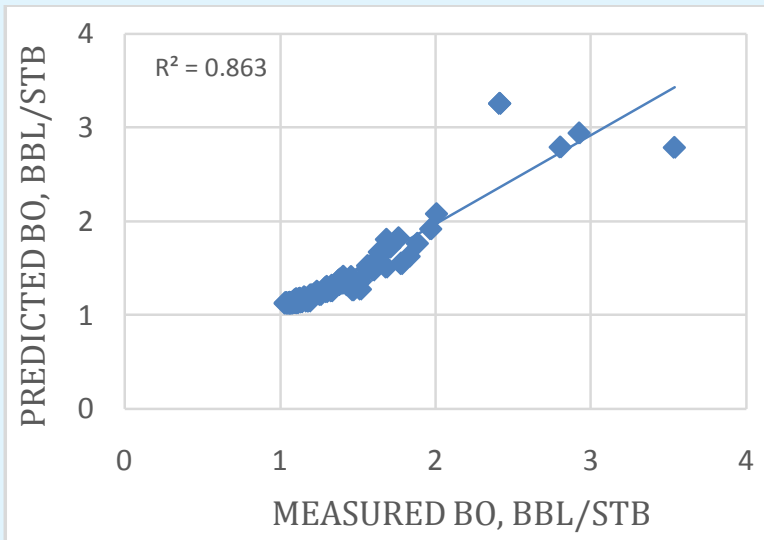

Figure 13: Almehaideb (1997).

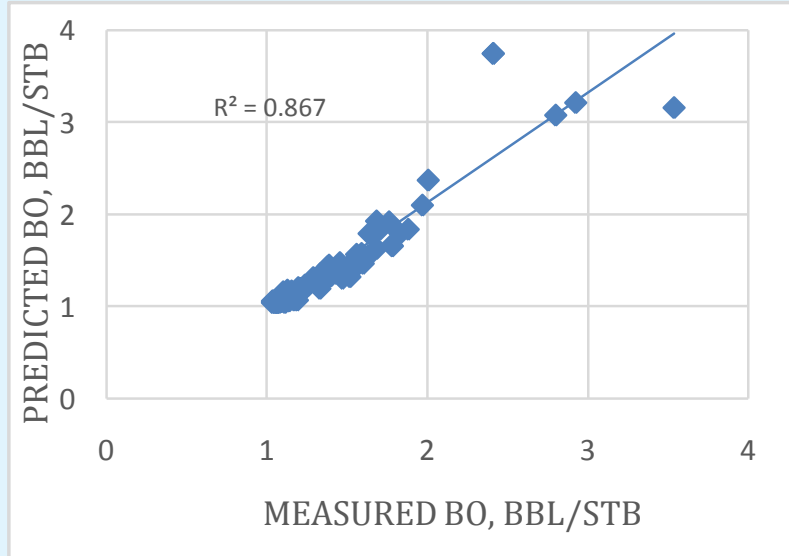

Figure 15: Sulaimon (2014).

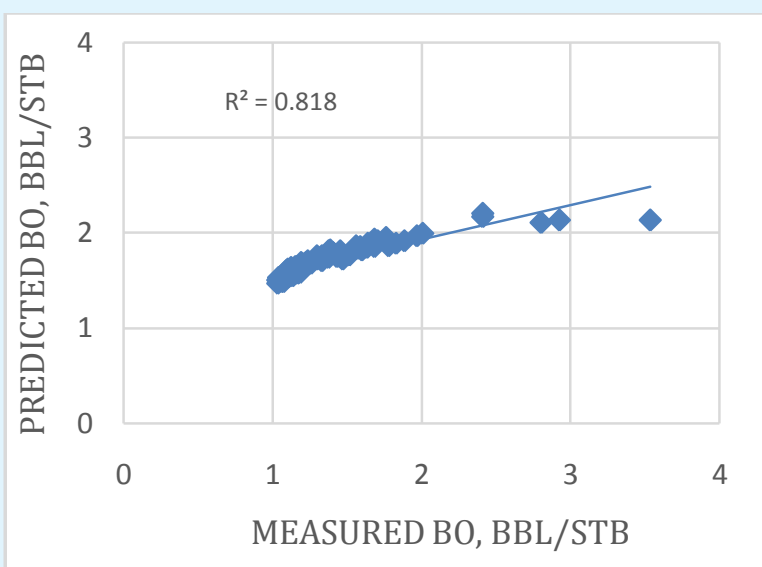

Figure 12: Farashad et al (1996).

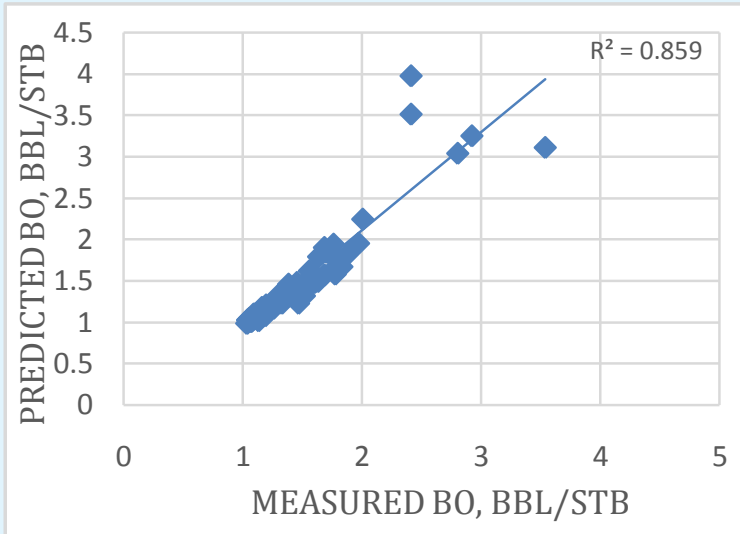

Figure 14: El-Banbi (2006).

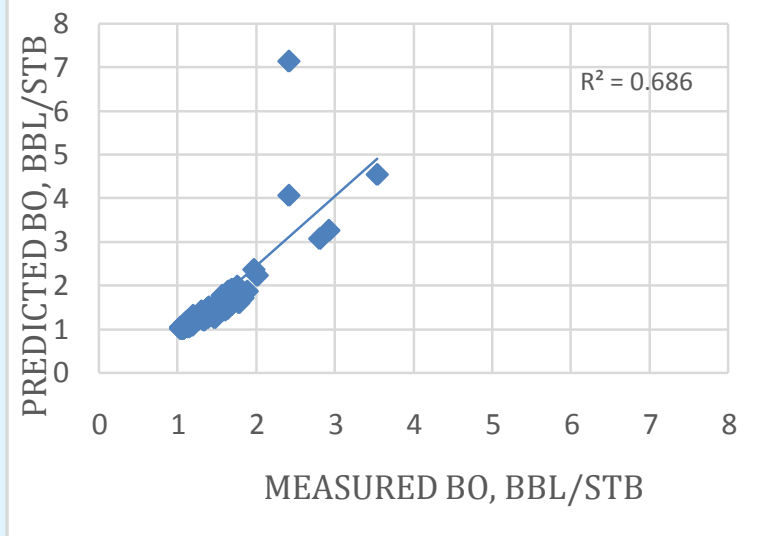

Figure 16: Dindoruk \& Christman (2001). 


\section{Petroleum \& Petrochemical Engineering Journal}

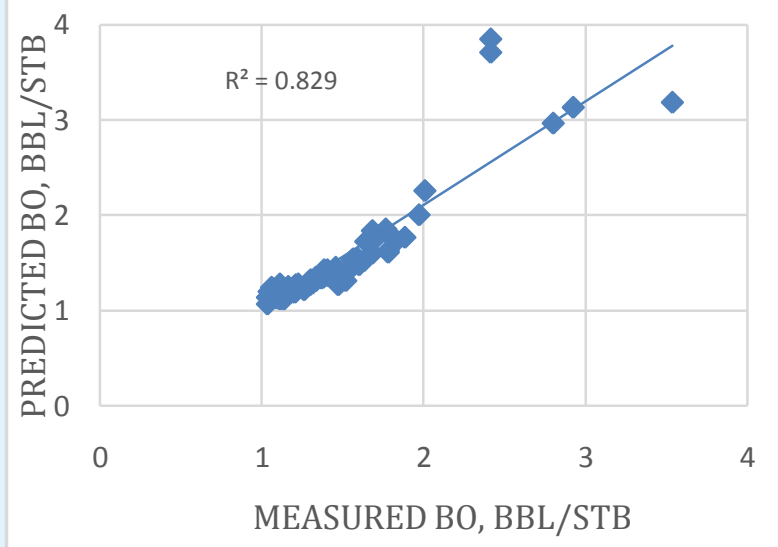

Figure 17: Bolondarzadeh et al.(2006).

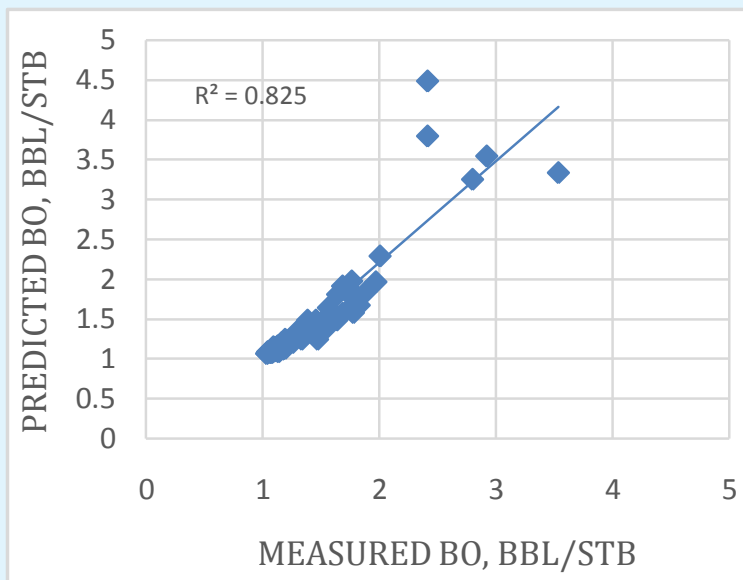

Figure 19: Hemmati \& Kharrat (2007).

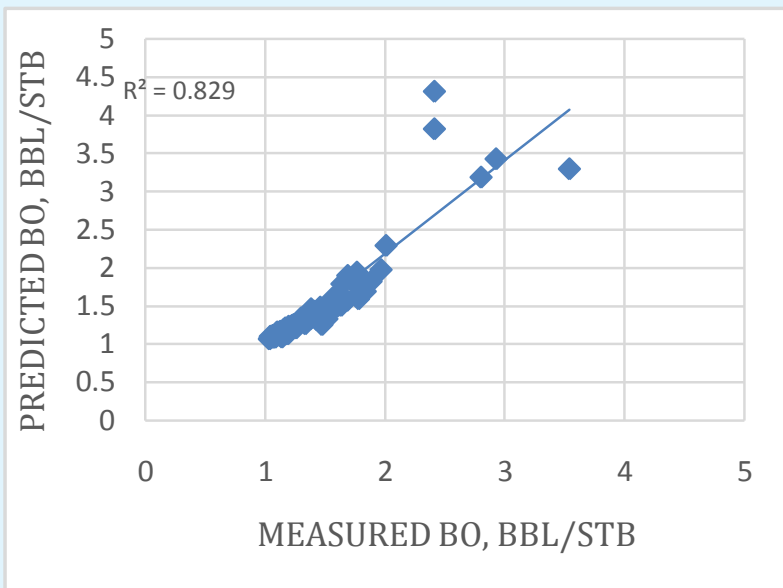

Figure 18: Merhen et al.(2006).

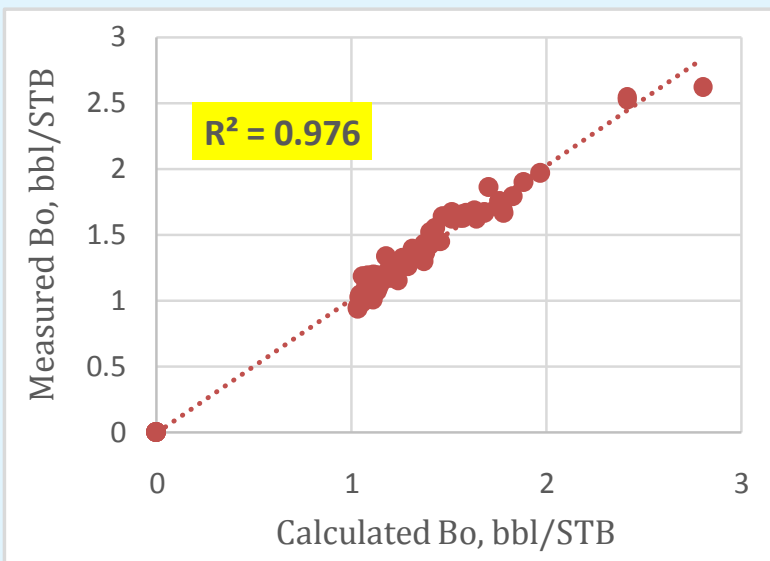

Figure 20: This study.
The coefficient of determination $\left(\mathrm{R}^{2}\right)$ indicates the strength of association between two variables, experimental data and predicted one. The closer the $\mathrm{R}^{2}$ to one, the closer the predicted values to the experimental data [1]. The cross plot figures indicate that the developed correlation has higher coefficient of determination $\left(\mathrm{R}^{2}=\right.$ 0.9769 ) than the published relations, so it is expected that it has high accuracy.

\section{Validation of Correlation}

Validity and applicability of the newly developed empirical correlations carried out through graphical error analysis using (89) data sets that were not used in the correlation development. Figure 21 shows cross plot of measured data and predicted one. We can observe that coefficient of determination $\left(\mathrm{R}^{2}=0.9412\right)$ which indicate high accuracy of this correlation related to validation samples. At this point, it should be mentioned the proposed correlations are only applicable to Egyptian oils and their applicability to other regions should be checked [7]. 


\section{Petroleum \& Petrochemical Engineering Journal}

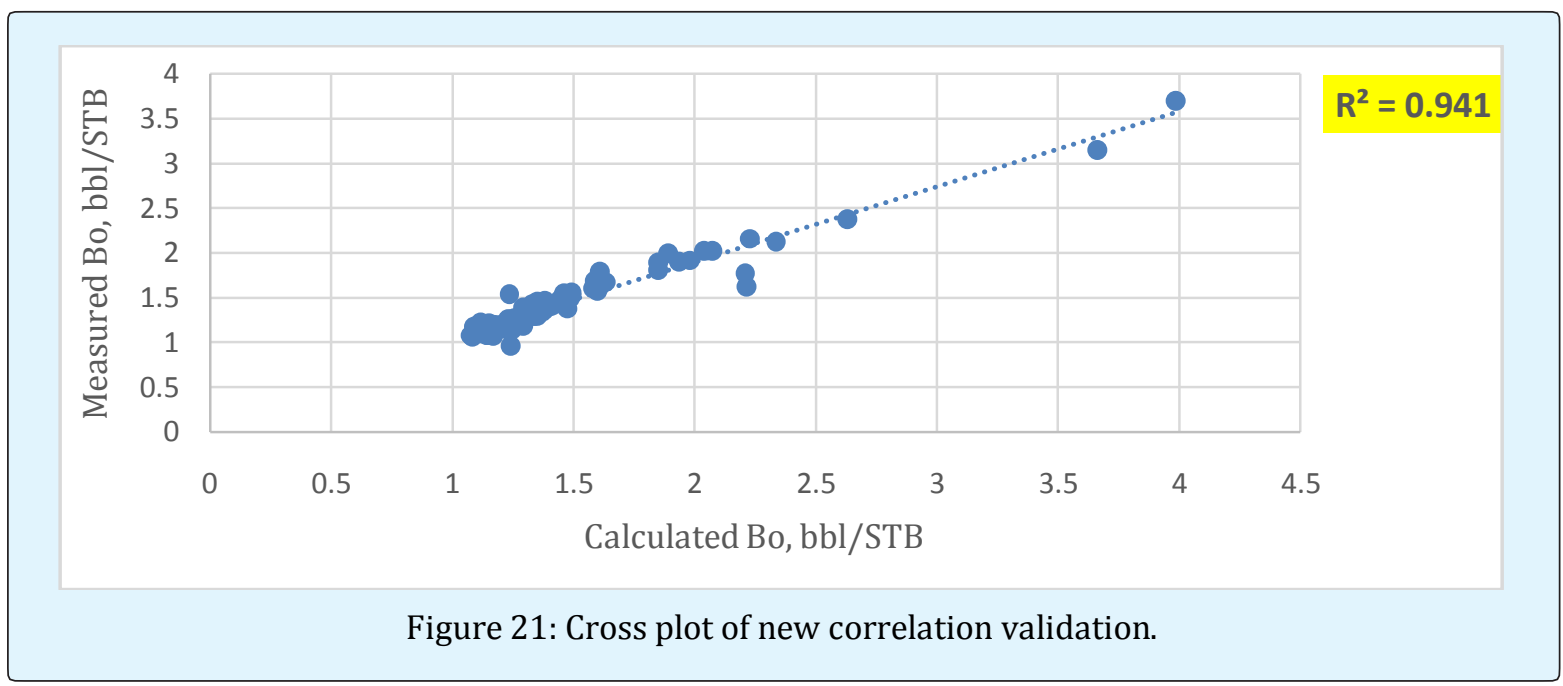

\section{Conclusion}

A novel correlation based on (100) data set covering different Egyptian oil production regions was developed to estimate bubble point oil FVF using non -linear regression model. The new correlation introduce all parameters found in published correlations in addition to separator pressure and temperature which consequently improve the developed correlation accuracy as had been discussed through the text. Experimental PVT analysis carried out to determine all parameters in the presented model. Comparative evaluation of the developed correlation and the well-known published correlations from the literature carried out using statistical and graphical error analyses. The obtained results indicate that, the developed correlation are more relevant and accurate to the Egyptian crude oils than the published ones as it shows high correlation coefficient $(\mathrm{r}=0.988)$ and lower relative errors $\left(E_{a}=4.591, E_{r}=-0.578\right)$. Model validation carried out on (89) oil samples through graphical error analysis where coefficient of determination reach to $\left(\mathrm{R}^{2}=0.9412\right)$ which indicate high reliability of the proposed correlation.

\section{Nomenclature}

\begin{tabular}{|c|c|}
\hline Oil FVF & Oil formation volume factor \\
\hline PVT & Pressure-Volume- Temperature \\
\hline $\mathrm{B}_{\mathrm{ob}}, \mathrm{bbl} / \mathrm{STB}$ & Bubble point oil formation volume factor \\
\hline Rs, scf/STB & Solution gas-oil ratio \\
\hline $\mathrm{T}^{\circ}{ }^{\circ} \mathrm{F}$ & Reservoir temperature \\
\hline$\gamma_{\mathrm{g}}$ & Gas specific gravity \\
\hline$\gamma_{\mathbf{o}}$ & Oil specific gravity \\
\hline $\mathrm{E}_{\mathrm{r}}$ & Average percent relative error \\
\hline $\mathrm{E}_{\mathrm{a}}$ & Average absolute percent relative error \\
\hline $\mathrm{E}_{\max }$ & Maximum absolute percent relative error \\
\hline $\mathrm{E}_{\min }$ & Minimum absolute percent relative error \\
\hline $\mathrm{S}$ & Standard deviation \\
\hline $\mathrm{E}_{\mathrm{rms}}$ & Root mean square error \\
\hline $\mathrm{r}$ & Correlation coefficient \\
\hline $\mathrm{GOR}, \mathrm{scf} / \mathrm{STB}$ & Gas -oil ratio \\
\hline $\mathrm{API}$ & American Petroleum Institute \\
\hline $\mathrm{STO}$ & Stock tank oil \\
\hline
\end{tabular}




\section{Petroleum \& Petrochemical Engineering Journal}

\begin{tabular}{|c|c|}
\hline$P_{\text {res, }}, p$ sig & Reservoir pressure \\
\hline$T_{\text {res }},{ }^{\circ} \mathrm{F}$ & Reservoir temperature \\
\hline$\rho_{\mathrm{ob}}, \mathrm{g} / \mathrm{cc}$ & Density of oil at bubble point \\
\hline $\mathrm{P}_{\mathrm{b}}, \mathrm{psig}$ & Bubble point pressure \\
\hline $\mathrm{P}_{\text {sep, }}, \mathrm{psig}$ & Separator pressure \\
\hline $\mathrm{T}_{\text {sep, }}{ }^{\circ} \mathrm{F}$ & Separator temperature \\
\hline $\mathrm{R}^{2}$ & Coefficient of determination \\
\hline
\end{tabular}

\section{References}

1. Fattah K, Lashin A (2016) Improved oil formation volume factor (Bo) correlation for volatile oil reservoirs: An integrated non-linear regression and genetic programming approach. Journal of King Saud University-Engineering Sciences.

2. Ahmed TH (1989) Hydrocarbon phase behavior, Gulf Pub Co., Houston, Texas.

3. Mahdiani MR, Kooti G (2016) The most accurate heuristic-based algorithms for estimating the oil formation volume factor. Petroleum 2(1): 40-48.

4. Fath AH (2017) Application of radial basis function neural networks in bubble point oil formation volume factor prediction for petroleum systems. Fluid Phase Equilibria 437: 14-22.

5. Edreder EA, Rahuma KM, Kalaflla HA (2016) Oil Formation Volume Factor Empirical Correlations for some Libyan Crude Oils. 3(1).

6. Hemmati M, Kharrat $R$ (2007) Evaluation of empirically derived PVT properties for Middle East crude oils. Scientia Iranica 14(4): 358-368.

7. El-hoshoudy A, Farag A, Ali O, El-Batanoney M, Desouky S, et al. (2013) New correlations for prediction of viscosity and density of Egyptian oil reservoirs. Fuel 112: 277-282.

8. El-Hoshoudy A, Desouky S, Betiha M, Abdelraouf S, Elaily M (2014) Mathematical correlation predicting stock tank oil density for Egyptian crude oils at standard conditions. International Journal of Oil, Gas and Coal Engineering 2(4): 55-58.

9. Wood DA (2018) Advances in Geo-Energy Research. 2.

10. Elsharkawy AM, Alikhan AA (1997) Correlations for predicting solution gas/oil ratio, oil formation volume factor, and undersaturated oil compressibility. Journal of Petroleum Science and Engineering 17(34): 291-302.

11. Standing M (1947) A pressure-volume-temperature correlation for mixtures of California oils and gases, Drilling and Production Practice, American Petroleum Institute, New York.

12. Vazquez M, Beggs HD (1977) Correlations for fluid physical property prediction. SPE Annual Fall Technical Conference and Exhibition, Society of Petroleum Engineers, Colorado.

13. Glaso O (1980) Generalized pressure-volumetemperature correlations. Journal of Petroleum Technology 32(5): 785-795.

14. Al-Marhoun MA (1988) PVT correlations for Middle East crude oils. Journal of Petroleum Technology 40(5): 650-666.

15. Abdul-Majeed GH, Salman NH (1988) An empirical correlation for oil FVF prediction. Journal of Canadian Petroleum Technology 27(6).

16. Dokla M, Osman M (1992) Correlation of PVT Properties for UAE Crudes (includes associated papers 26135 and 26316). SPE Formation Evaluation 7(1): 41-46.

17. Al-Marhoun MA (1992) New Correlation for formation Volume Factor of oil and gas Mixtures. Journal of Canadian Petroleum Technology 31(3).

18. Macary S, El-Batanoney M (1993) Derivation of PVT correlations for the Gulf of Suez crude oils. Journal of The Japan Petroleum Institute 36(6): 472-478.

19. Omar M, Todd A (1993) Development of new modified black oil correlations for Malaysian crudes. SPE Asia Pacific oil and gas conference, Society of Petroleum Engineers, Singapore. 


\section{Petroleum \& Petrochemical Engineering Journal}

20. Petrosky G, Farshad F (1993) Pressure-volumetemperature correlations for Gulf of Mexico crude oils, SPE annual technical conference and exhibition, Society of Petroleum Engineers, Texas.

21. Kartoatmodjo T, Schmidt Z (1994) Large data bank improves crude physical property correlations. Oil and Gas Journal 92.

22. Frashad F, LeBlanc J, Garber J, Osorio J (1996) Empirical PVT correlations for Colombian crude oils. SPE Latin America/Caribbean petroleum engineering conference, Society of Petroleum Engineers, Trinidad.

23. Almehaideb R (1997) Improved PVT correlations for UAE crude oils. Middle east oil show and conference, Society of Petroleum Engineers, Bahrain.

24. El-Banbi AH, Fattah KA, Sayyouh H (2006) New modified black-oil PVT correlations for Gas condensate and volatile oil fluids. SPE Annual Technical Conference and Exhibition, Society of Petroleum Engineers, Texas, USA.

25. Sulaimon A, Ramli N, Adeyemi B, Saaid I (2014) New Correlation for Oil Formation Volume Factor. SPE Nigeria Annual International Conference and Exhibition, Society of Petroleum Engineers, Nigeria.

26. Dindoruk B, Christman PG (2001) PVT properties and viscosity correlations for Gulf of Mexico oils. SPE annual technical conference and exhibition, Society of Petroleum Engineers.

27. Bolondarzadeh A, Hashemi S, Solgani B (2006) The new PVT generated correlations of Iranian oil properties. 4th Iranian Petroleum Engineering Student conference.

28. Mehran F, Movagharnejad K, Didanloo A (2006) New correlation for estimation of formation volume factor and bubblepoint pressure for Iranian oil Fields. 1st Iranian Pet. Eng. Congress., pp: 17.
29. Karimnezhad M, Heidarian M, Kamari M, Jalalifar $H$ (2014) A new empirical correlation for estimating bubble point oil formation volume factor. Journal of Natural Gas Science and Engineering 18: 329-335.

30. Salehinia S, Salehinia Y, Alimadadi F, Sadati SH (2016) Forecasting density, oil formation volume factor and bubble point pressure of crude oil systems based on nonlinear system identification approach. Journal of Petroleum Science and Engineering 147: 47-55.

31. Moradi B, Malekzadeh E, Mohammad A, Awang M, Moradie P (2013) New Oil Formation Volume Factor Empirical Correlation for Middle East Crude Oils. International Journal of Petroleum and Geoscience Engineering 1(1): 12-23.

32. El Aily M, Khalil M, Desouky S, Batanoni M, Mahmoud M (2013) Experimental studies on constant massvolume depletion of gas-condensate systems. Egyptian Journal of Petroleum 22(1): 129-136.

33. Ahmed T (2006) Reservoir engineering handbook. Gulf Professional Publishing pp: 1376.

34. Khan MN, Bilal HM, Shoaib M, Manzoor AA, Shaukat W, et al. (2012) Fluid Characterization of a Retrograde Gas Condensate Reservoir for the Simulation Study. Society of Petroleum Engineers, SPE/PAPG Annual Technical Conference, Islamabad, Pakistan.

35. Dalgaard P (2008) Introductory statistics with R. $2^{\text {nd }}$ (Edn.), Springer-Verlag New York, pp: 364.

36. McCain WD (1990) The properties of petroleum fluids. PennWell Books.

37. Lohrenz J, Bray BG, Clark CR (1964) Calculating viscosities of reservoir fluids from their compositions. Journal of Petroleum Technology 16(10).

38. Katz DL (1942) Prediction of the shrinkage of crude oils. Drilling and Production Practice, American Petroleum Institute, New York.
El-hoshoudy AN and Desouky SM. Numerical Prediction of Oil Formation Volume Factor at Bubble Point for Black and Volatile Oil Reservoirs Using NonLinear Regression Models. Pet Petro Chem Eng J 2018, 2(2): 000145.
Copyright $(\subset$ El-hoshoudy AN and Desouky SM. 